\title{
Physical properties and consumer acceptability of basic muffin made from pumpkin puree as butter replacer
}

\author{
*Arifin, N., Siti Nur Izyan, M.A. and Huda-Faujan, N. \\ Food Biotechnology Programme, Faculty of Science and Technology, Universiti Sains Islam Malaysia, \\ 71800 Nilai Negeri Sembilan
}

\author{
Article history: \\ Received: 20 February 2019 \\ Received in revised form: 4 \\ July 2019 \\ Accepted: 6 July 2019 \\ Available Online: 17 July \\ 2019
}

\section{Keywords:}

Muffin,

Pumpkin puree,

Texture profile,

Sensory acceptability

\section{DOI:}

https://doi.org/10.26656/fr.2017.3(6).090

\begin{abstract}
Muffin is a product that highly appreciated by consumers and one of the main ingredients of muffin production is butter which contains high cholesterol and saturated fat. However, in recent years, consumers' demand increases for healthier ingredient and similar taste to the origin. Therefore, this study was carried out to evaluate the physical properties and sensory acceptability of butter replacement with pumpkin puree on basic muffin ingredient. Muffin formulations of three were formulated to replace butter with pumpkin puree at concentrations: 20\% (Formulation A), 25\% (Formulation B); and 30\% (Formulation C). A muffin formulated with butter was served as a control. All muffins were analysed for muffin's height, texture profiles, colour, and consumer acceptability. Results found that replacement of pumpkin puree in muffin formulations increased $(P>0.05)$ muffin height. Replacement of pumpkin puree in muffin formulations (from $30 \%$ to $20 \%)$ was also significantly increased $(P<0.05)$ hardness and chewiness of muffins as compared to control muffin. However, the cohesiveness of muffins was not differed $(P>0.05)$ among all formulations. Analysis of colour found that lightness $\left(L^{*}\right)$ of pumpkin puree muffins significantly decreased $(P<0.05)$ as compared to control muffin when the amount of pumpkin puree was increased in muffin formulations (from $20 \%$ to $30 \%$ ). However, replacement of pumpkin puree in muffin formulations increased $(P>0.05) a^{*}$ (green to red) and $b^{*}$ (blue to yellow) values of muffins. In the assessment of pumpkin puree muffin acceptability, Hedonic test obtained that consumers preferred muffin with $30 \%$ of pureed pumpkin replacement with control muffin in all attributes (colour, aroma, texture, taste, and overall acceptance) and comparable $(P>0.05)$ with control muffin. Thus, these findings suggested that $30 \%$ pumpkin puree was feasible to be used as butter replacer in muffin formulation.
\end{abstract}

\section{Introduction}

Muffin can be categorised as a quick bread product which made with baking powder as a leavening agent. The principal ingredients of muffins include flour, sugar, fat, and egg. Each ingredient plays an important role in the structure, appearance, and eating quality of the final product. Butter is commonly used as a fat ingredient in muffin formulation. It contributes to desirable mouthfeel, unique texture in muffin as well as provide unique aroma, and flavour extension (Brown, 2011). However, butter contains high cholesterol and saturated fats (Hendricks et al., 1999) which can lead to increase cholesterol in human blood (Lichtenstein et al., 1999).

Pumpkin puree is a product from pumpkin flesh which a member of Cucurbitaceae family (Hosseini Ghaboos et al., 2016). Pumpkin puree contains a lot of $\beta$ - carotene pigment which are precursors of vitamin A and their consumption has been associated to prevent cardiovascular diseases and some cancers (Provesi et al., 2011). This pigment provides an intense orange-yellow colour to pumpkin puree and also has a sweet taste that might contribute to good flavour to the end product (Scheuer et al., 2014). Besides, pumpkin puree also contains vitamin $\mathrm{B}_{1}, \mathrm{~B}_{2}, \mathrm{~B}_{6}, \mathrm{C}, \mathrm{E}$, and $\mathrm{K}$, contains low energy and a considerable amount of fibre (Jacobo et al., 2011).

Recently, Schatzel (2018) reported that butter can be replaced with other fruit sources include pumpkin puree, apple sauce, or avocado in baked products. However, replacing of fruit source in foods is challenging since it may negatively affect the physical properties and sensory acceptability of the foods. For examples, biscuit formulated with different ratio of pumpkin puree and 
wheat flour decreased in diameter and thickness $(P>0.05)$ but significantly $(P<0.05)$ increased in bulk density when ratio of pumpkin puree increased in biscuit formulation Furthermore, overall acceptability of the biscuit was found significantly decreased $(P<0.05)$ when ratio of pumpkin puree and wheat flour increased at 40:60 (Gurung et al., 2016).

Previously, several researchers evaluated physical properties and sensory acceptability of bakery products with pumpkin puree in bread (Scheuer et al., 2014), biscuit (Gurung et al., 2016), cake (Karaoğlu and Kotancilar, 2009), and cookie (Kia and Hosseini Ghaboos, 2018). However, limited scientific studies were carried out to use pumpkin puree as butter replacer in muffin production. Thus, the aim of this research was to replace butter in basic muffin formulation with pumpkin puree. Furthermore, the objectives of the study were to determine the physical properties and sensory acceptance of muffin made from pumpkin puree.

\section{Materials and methods}

\subsection{Materials}

All ingredients of basic muffin including all-purpose flour (Anchor), sugar, salt, baking powder, egg, pumpkin, milk, and butter were bought from a supermarket in Nilai, Negeri Sembilan, Malaysia.

\subsection{Sample preparation}

\subsubsection{Pumpkin puree}

Pumpkin puree was prepared according to Baier and co-researchers (2018). Ripe pumpkin fruit was brought from a supermarket in Nilai, Negeri Sembilan, Malaysia. Prior to puree preparation, pumpkin was cut into halves and the seeds and strings were removed to obtain the orange flesh. The pumpkin was then cut into small cubes and washed using distilled water. The cut pumpkin was roasted uncovered using the oven (Cornell), at $200^{\circ} \mathrm{C}$ for 40 to 60 mins. The aim of roasting pumpkin was to add extra depth to the flavour of pumpkin and makes it a little sweeter and richer. Lastly, the skin was peeled off and the pumpkin was put in the processor to produce a puree.

\subsubsection{Muffin production}

Production of the muffin was adopted from RomeroLopez et al. (2011). A control sample of the muffin was formulated using butter while the other three formulations of muffins were formulated with different percentage of pumpkin puree to replace butter. The three muffin formulations were A (muffin with $20 \%$ pumpkin puree), B (muffin with $25 \%$ pumpkin puree), and $\mathrm{C}$ (muffin with $30 \%$ pumpkin puree) (Table 1). Initially, butter or pumpkin puree and sugar were added into a mixer bowl and mixed together in an electric mixer. Then, $90 \mathrm{~g}$ of whole eggs were added and mix thoroughly into the mixture. Next, flour (300 g), baking powder $(15 \mathrm{~g})$, sugar $(195 \mathrm{~g})$, and salt $(7.5 \mathrm{~g})$ were mixed and sifted before adding into the mixer bowl. After that, milk $(225 \mathrm{~mL})$ was gradually added into the mixture while mixing ingredient until homogeneous. Finally, the muffins were baked in a pre-heated oven at $200^{\circ} \mathrm{C}$ for 30 mins. The muffins were allowed to cool down at room temperature $\left(25^{\circ} \mathrm{C}\right)$ before analysis.

\subsection{Physical analysis}

\subsubsection{Muffin height determination}

Muffin height was measured from the top of muffin (peak) to the bottom of muffin cup before baking and after $1 \mathrm{hr}$ of cooling at room temperature $\left(25^{\circ} \mathrm{C}\right)$ using a ruler in centimetre $(\mathrm{cm})$ (Scheuer et al., 2014).

\subsubsection{Texture analysis}

A double compression test was performed with spherical probe using 0.25 inch of diameter using Texture Analyzer (TA-XT Plus Model, Stable Micro System, Surrey, London) (Altamirano-Fortoul et al., 2013). The initial height of compression was set at $50 \%$ with speed $1 \mathrm{~mm} / \mathrm{s}$ and $5 \mathrm{~s}$ waiting time was used for this analysis. The texture parameters analysed were hardness, springiness, cohesiveness, and chewiness.

Table 1. Muffin formulations

\begin{tabular}{lcccc}
\hline \multicolumn{1}{c}{ Ingredients } & Control (butter) & $\begin{array}{c}\text { Formulation A } \\
\text { (Muffin with 20\% } \\
\text { pumpkin puree) }\end{array}$ & $\begin{array}{c}\text { Formulation B } \\
\text { (Muffin with 25\% } \\
\text { pumpkin puree) }\end{array}$ & $\begin{array}{c}\text { Formulation C } \\
\text { (Muffin with 30\% } \\
\text { pumpkin puree) }\end{array}$ \\
\hline All-purpose flour (Anchor) (g) & 300 & 300 & 300 & 300 \\
Pumpkin Puree (g) & - & 30 & 37.5 & 45 \\
Egg (g) & 90 & 90 & 90 & 90 \\
Milk (ml) & 225 & 225 & 225 & 225 \\
Butter (g) & 150 & - & - & - \\
Sugar (g) & 195 & 195 & 195 & 195 \\
Salt (g) & 7.5 & 7.5 & 7.5 & 7.5 \\
Baking powder (g) & 15 & 15 & 15 & 15 \\
\hline
\end{tabular}




\subsubsection{Colour measurement}

Determination of muffin colour was analysed using colorimeter (LabScan ${ }^{\circledR} \mathrm{XE}$ Spectrophotometer Model, HunterLab) based on $L^{*} a^{*} b^{*}$ colour scale system. $L^{*}$ value represents lightness/darkness, $a^{*}$ value represent redness/greenness and $b^{*}$ value represents yellowness/ blueness. Prior to analysis, each muffin $(20 \mathrm{~g})$ was ground to small particles before putting in a specific plate. Colour of the muffins were automatically measured and displayed in computer screen according to the manufacturer's instruction.

\subsection{Sensory analysis}

Determination of consumer acceptability was done using Hedonic test according to Meilgaard et al. (2007). The analysis was conducted in individual booths at Sensory Laboratory, Universiti Sains Islam Malaysia, Nilai, Malaysia. A total of 60 consumer panellists participated in this test to evaluate muffin with $20 \%$, $25 \%$, and $30 \%$ of pumpkin puree compared to butter. A scale of 9-points was used in this test which ranging from scale 1 (extremely dislike) to scale 9 (extremely like). Each panellist evaluated attributes of appearance, colour, texture, taste, and overall acceptance. Each muffin sample was cut into a rectangle shaped and served to panellists with random three-random-digit number to avoid bias.

\subsection{Statistical analysis}

All data were analysed with one-way analysis of variance or ANOVA, followed by Tukey's test to compare the means between samples. Data was analysed using Minitab® software, Release 16

(McKenzie et al., 1995) and the statistical significance was established at $(P<0.05)$. All experiments was carried out in triplicate.

\section{Results and discussion}

\subsection{Muffin physical properties}

Table 2 shows the height of muffin with $20 \%, 25 \%$ and $30 \%$ of pumpkin puree in muffin formulations. Results found that replacement of pumpkin puree in muffin increased $(P>0.05)$ the height of muffin compared to control muffin which was prepared with butter. The height of butter muffin was $4.90 \mathrm{~cm}$ while the ranged of pumpkin puree was from 5.00 to $5.13 \mathrm{~cm}$ (Table 2). The increment in height of the muffin might be due to the starch properties belong to the pumpkin. Indeed, the starch content of pumpkin in the mature stage was $117.45 \mathrm{mg} / \mathrm{g}$ (Sharma and Ramano Rao, 2013). Starch has the ability to absorb water through starch gelatinisation and resulted in a higher volume of the product. Previously, Khalil (1998) stated that there was an increase in height in the low fat cake as carbohydratebased fat replacers were used along with emulsifier. This could explain why the muffin height in pumpkin puree muffins was significantly higher $(P<0.05)$ than in control muffin.

Results of muffin's texture are also shown in Table 2 and obtained that hardness and chewiness of pumpkin puree muffin were significantly higher $(P<0.05)$ than in control muffin. The hardness and chewiness of control muffin were $164.98 \mathrm{~N}$ and $31.47 \mathrm{~N} / \mathrm{cm}$, respectively. However, the range of hardness and chewiness of pumpkin puree muffins were from 275.73 to $352.30 \mathrm{~N}$, and from 62.82 to $97.04 \mathrm{~N} / \mathrm{cm}$, respectively. In fact, hardness was defined as the maximum peak force during the first compression cycle (first bite) indicating the hardness or softness of the product. Increment of hardness in pumpkin puree muffin might be associated with tenderising action of gluten, starch, and water. The increasing amount of pumpkin puree in muffins were significantly $(P<0.05)$ promote a consistent soft muffin. The muffin hardness' of formulation A (20\% pumpkin puree), formulation B (25\% pumpkin puree), and formulation $\mathrm{C}$ (30\% pumpkin puree) were $352.30 \mathrm{~N}$, $325.72 \mathrm{~N}$, and $275.73 \mathrm{~N}$, respectively. In fact, Kia and Hosseini Ghaboos (2018) also reported that filling cookies prepared with higher percentage of pumpkin puree than dates obtained softer texture than formulations with lower percentage of pumpkin puree than dates in filling cookie.

The increasing amount of pumpkin puree in muffins was also consistently decreased $(P<0.05)$ the chewiness. These findings were parallel to the hardness as

Table 2. Height and texture profile for muffin with various percentage of pumpkin puree

\begin{tabular}{lcccc}
\hline \multicolumn{1}{c}{ Formulation } & Control (butter) & $\begin{array}{c}\text { Formulation A } \\
\text { (Muffin with 20\% } \\
\text { pumpkin puree) }\end{array}$ & $\begin{array}{c}\text { Formulation B } \\
\text { (Muffin with 25\% } \\
\text { pumpkin puree) }\end{array}$ & $\begin{array}{c}\text { Formulation C } \\
\text { (Muffin with 30\% } \\
\text { pumpkin puree) }\end{array}$ \\
\hline Height (cm) & $4.90 \pm 0.20^{\mathrm{a}}$ & $5.13 \pm 0.12^{\mathrm{a}}$ & $5.00 \pm 0.10^{\mathrm{a}}$ & $5.13 \pm 0.15^{\mathrm{a}}$ \\
Hardness (N) & $164.98 \pm 1.16^{\mathrm{d}}$ & $352.30 \pm 2.57^{\mathrm{a}}$ & $325.72 \pm 0.85^{\mathrm{b}}$ & $275.73 \pm 2.80^{\mathrm{c}}$ \\
Springiness (cm) & $0.91 \pm 0.00^{\mathrm{b}}$ & $0.97 \pm 0.02^{\mathrm{a}}$ & $0.97 \pm 0.02^{\mathrm{a}}$ & $0.97 \pm 0.01^{\mathrm{a}}$ \\
Chewiness (N/cm) & $31.47 \pm 4.59^{\mathrm{d}}$ & $97.04 \pm 1.72^{\mathrm{a}}$ & $85.86 \pm 1.48^{\mathrm{b}}$ & $62.82 \pm 0.91^{\mathrm{c}}$ \\
Cohesiveness (ratio) & $0.24 \pm 0.01^{\mathrm{a}}$ & $0.24 \pm 0.02^{\mathrm{a}}$ & $0.24 \pm 0.01^{\mathrm{a}}$ & $0.24 \pm 0.02^{\mathrm{a}}$ \\
\hline
\end{tabular}

Superscripts within same row with different letter are significantly different at $(P>0.05)$ 
chewiness was defined as the energy required to masticate a solid food to a state ready for swallowing (Karaoğlu and Kotancilar, 2009). Pumpkin puree muffins were also significantly $(P<0.05)$ decreased springiness of muffin. Indeed, springiness is related to the height that the food recovers during the time that elapses between the end of the first bite and the start of the second bite. In this study, the springiness value of butter muffin was $0.91 \mathrm{~cm}$ while the springiness values of all pumpkin puree muffin were $0.97 \mathrm{~cm}$ (Table 2). Cohesiveness is defined as the ratio of the positive force during the second compression to that during the first compression. This parameter is the strength of internal bonds which make up the body of the product (Sariçoban et al., 2009). From Table 2, cohesiveness values of butter muffin and all pumpkin puree muffin formulations were 0.24 .

\subsection{Muffin colour}

Colour is one of the most important attributes that affect directly the consumer preference of any product. The colour for $L^{*}, a^{*}$ and $b^{*}$ values were statistically analysed in Table 3 . In fact, $L^{*}$ values represent lightness/darkness, $a^{*}$ represent red/green colour, and $b^{*}$ represent yellow/blue colour. Control muffin was found the highest values of $L^{*}$ (71.30) as compared to muffin with pumpkin puree (63.61 to 66.35) suggesting darker colour of the latter samples. Perhaps, this finding can be attributed to the occurrence of non-enzymatic browning between beta-carotene pumpkin puree and flour upon baking muffin. Similarly, Zhou et al. (2013) reported that the occurrence of non-enzymatic reaction also took place together with oxidation and isomerization of betacarotene had changed the colour parameters of pumpkin candy. While the low $L^{*}$ value of control muffin could be due to the pale colour of the butter as compared to pumpkin puree. Pumpkin is rich with $\beta$-carotene content contribute to a very bright orange colour of pumpkin. However, the $L^{*}$ value (darkness to whiteness) of pumpkin puree muffin decreased as the percentage of pumpkin puree increased as shown in Table 3 .

On the other hand, $a^{*}$ (red/green) and $b^{*}$ (yellow/ blue) values of the muffins showed no significant difference $(P>0.05)$ among all the samples. Control muffin which produced using butter had the least $a^{*}$ (6.77) and $b^{*}$ (36.53) values while formulation C (muffin with $30 \%$ pumpkin puree) obtained the highest value of $a^{*}(10.45)$ and $b^{*}$ (40.18). The high values of both $a^{*}$ and $b^{*}$ in muffin with pumpkin puree could be also due to the yellow/orange pigments of $\beta$-carotene. The redness $\left(a^{*}\right)$ and yellowness $\left(b^{*}\right)$ values in cookies also increased when the percentage of pumpkin puree as filling increased and was significantly higher $(P<0.05)$ than the control sample which used dates as cookies filling (Kia and Hosseini Ghaboos, 2018).

\subsection{Muffin consumer acceptability}

Table 4 presents data of hedonic test of muffins by consumer panellists. Results obtained that the acceptability of control muffin in terms of the aroma, texture, taste, and overall acceptance were the highest $(P<0.05)$ compared to all pumpkin puree muffin except for colour. The mean scores of attributes aroma, texture, taste, and overall acceptance of control muffin were $6.80,6.32,7.20$, and 7.02, respectively. As expected, panellists most preferred yellow colour of muffin with $30 \%$ pumpkin puree which the mean scores were 6.62 $(P>0.05)$. The higher amount of pumpkin puree in muffin provide better appearance and pleasant of yellow colour since pumpkin flesh contained $\beta$-carotene (redorange colour pigment) which this was also correlated with $b^{*}$ value $(40.18)$ of the muffin (formulation $\mathrm{C}$ ). Several researchers also found that yellow colour of food products increased mean scores of panellists in colour attribute. For example, Kia and Hosseini Ghaboos (2018) found that colour of cookies filling with $25 \%$ pumpkin puree was the most like (4.10) compared to without pumpkin puree filling (3.90) $(P>0.05)$. In addition, the chickpea flour that contributed to yellowish colour also increased panellists' mean scores when the percentage was increased in imitation chicken nugget product formulations (Sharima-Abdullah et al., 2018).

Panellists most preferred aroma, taste, texture, and overall acceptance of control muffin (butter formulation) (Table 4) because butter have a distinct flavour and aroma as well as provide mouthfeel sensation for better consumption (Rios et al., 2014). In the recent year, Mohan et al. (2018) reported that increasing ratio of avocado puree to butter in cookies decreased $(P>0.05)$ the mean scores of attributes aroma, taste, flavour, and overall acceptance compared to control (butter cookies). Furthermore, increasing ratio pumpkin puree to date in cookies filling were also significantly $(P<0.05)$ decreased panellists' mean scores of flavour, and overall acceptance. However, in this study, it was found that the mean scores of attributes of aroma, taste, texture, and overall acceptance of pumpkin puree muffin increased with the increasing amount of pumpkin puree replacement (Table 4). Therefore, it is suggested that the addition of pumpkin puree has a feasibility to replace butter in muffin formulation. According to Colla et al. (2018), a successful fat-replacement product must replicate texture, mouthfeel, and flavour of the original fat.

\section{Conclusion}

This study demonstrated that the pumpkin puree 
Table 3. Colour analysis using hunter lab for muffin with various percentage of pumpkin puree

\begin{tabular}{ccccc}
\hline Formulation & Control (butter) & $\begin{array}{c}\text { Formulation A } \\
\text { (Muffin with 20\% } \\
\text { pumpkin puree) }\end{array}$ & $\begin{array}{c}\text { Formulation B } \\
\text { (Muffin with 25\% } \\
\text { pumpkin puree) }\end{array}$ & $\begin{array}{c}\text { Formulation C } \\
\text { (Muffin with 30\% } \\
\text { pumpkin puree) }\end{array}$ \\
\hline$L^{*}$ & $71.30 \pm 2.30^{\mathrm{a}}$ & $66.35 \pm 2.98^{\mathrm{ab}}$ & $64.81 \pm 3.55^{\mathrm{ab}}$ & $63.61 \pm 0.81^{\mathrm{b}}$ \\
$a^{*}$ & $6.77 \pm 2.02^{\mathrm{a}}$ & $10.02 \pm 2.09^{\mathrm{a}}$ & $9.52 \pm 1.22^{\mathrm{a}}$ & $10.45 \pm 1.74^{\mathrm{a}}$ \\
$b^{*}$ & $36.83 \pm 1.01^{\mathrm{a}}$ & $38.02 \pm 0.68^{\mathrm{a}}$ & $39.21 \pm 2.03^{\mathrm{a}}$ & $40.18 \pm 1.11^{\mathrm{a}}$ \\
\hline
\end{tabular}

Superscripts within same row with different letter are significantly different at $(P>0.05)$

Table 4. Mean scores of hedonic test of muffin with various percentage of pumpkin puree

\begin{tabular}{ccccc}
\hline Formulation & Control (butter) & $\begin{array}{c}\text { Formulation A } \\
\text { (Muffin with 20\% } \\
\text { pumpkin puree) }\end{array}$ & $\begin{array}{c}\text { Formulation B } \\
\text { (Muffin with 25\% } \\
\text { pumpkin puree) }\end{array}$ & $\begin{array}{c}\text { Formulation C } \\
\text { (Muffin with 30\% } \\
\text { pumpkin puree) }\end{array}$ \\
\hline Colour & $6.57 \pm 1.58^{\mathrm{a}}$ & $6.48 \pm 1.67^{\mathrm{a}}$ & $6.58 \pm 1.49^{\mathrm{a}}$ & $6.62 \pm 1.54^{\mathrm{a}}$ \\
Aroma & $6.80 \pm 1.59^{\mathrm{a}}$ & $5.92 \pm 1.60^{\mathrm{b}}$ & $6.25 \pm 1.79^{\mathrm{ab}}$ & $6.57 \pm 1.53^{\mathrm{ab}}$ \\
Texture & $6.32 \pm 1.50^{\mathrm{a}}$ & $5.08 \pm 1.83^{\mathrm{b}}$ & $5.35 \pm 1.81^{\mathrm{b}}$ & $5.55 \pm 2.00^{\mathrm{ab}}$ \\
Taste & $7.20 \pm 1.21^{\mathrm{a}}$ & $5.70 \pm 1.37^{\mathrm{b}}$ & $6.02 \pm 1.24^{\mathrm{b}}$ & $6.70 \pm 1.00^{\mathrm{a}}$ \\
Overall Acceptance & $7.02 \pm 1.46^{\mathrm{a}}$ & $6.05 \pm 1.21^{\mathrm{b}}$ & $6.18 \pm 1.19^{\mathrm{b}}$ & $6.82 \pm 1.11^{\mathrm{a}}$ \\
\hline
\end{tabular}

Superscripts within same row with different letter are significantly different at $(P>0.05)$

muffin significantly increased $(P<0.05)$ hardness and chewiness of muffin compared to control muffin. Increasing of pumpkin puree percentage for butter replacer in muffin changed the darkness, redness, and yellowness of muffin products. In the overall acceptance of pumpkin puree muffin, it was obtained that $30 \%$ of pumpkin puree replacement in muffin was most acceptable and might be due to attractive yellow colour and better sweet taste of pumpkin. Thus, this study concluded that $30 \%$ pumpkin puree has the potential to be used as butter replacer in the formulation of muffin. Furthermore, the nutritional properties and caloric value of this pumpkin puree muffin will be studied in the future project.

\section{Conflict of Interest}

No conflict of interest

\section{Acknowledgments}

The authors are grateful to Faculty Science and Technology, Universiti Sains Islam Malaysia, Malaysia for the use of all laboratory facilities, apparatus, and financial support of this entire work. Special thanks also go to Mrs. Rina Wahap, Mrs. Normah Haron, Mrs. Norhafiza Abdul Ghafar, and to all laboratory assistants of Faculty Science and Technology, Universiti Sains Islam Malaysia, for their assistance in this work.

\section{References}

Altamirano-Fortoul, R., Hernando, I. and Rosell, C.M. (2013). Texture of bread crust: puncturing settings effect and its relationship to microstructure. Journal of Texture Studies, 44(2), 85-94. https:// doi.org/10.1111/j.1745-4603.2012.00368.x

Baier, L., Lacey, Meg, Boone, M., Owens, J., Paul, P. and Owens-Peters, S. (2018). How to Make Pumpkin Puree. Retrieved from https:// www.asweetpeachef.com/how-to-make-pumpkinpuree/

Brown A. (2011). Quick bread, In Brown, A. (Ed) Understanding Food: Principle and Preparation. $4^{\text {th }}$ ed. Belmont, CA: Wadsworth Cengage Learning.

Colla, K., Costanzo, A. and Gamlath, S. (2018). Fat Replacers in Baked Food Products. Foods, 7(12), 192. https://doi.org/10.3390/foods 7120192

Gurung, B., Ojha, P. and Subba, D. (2016). Effect of mixing pumpkin puree with wheat flour on physical, nutritional and sensory characteristics of biscuit. Journal of Food Science and Technology Nepal, 9, 85-89. https://doi.org/10.3126/jfstn.v9i0.13142

Hosseini Ghaboos, S.H., Seyedain Ardabili, S.M., Kashaninejad, M., Asadi, G. and Aalami, M. (2016). Combined infrared-vacuum drying of pumpkin slices. Journal of Food Science and Technology, 53 (5), 2380-2388. https://doi.org/10.1007/s13197-0162212-1

Jacobo, V.N., de Jesus, Z.M.J., Gallegos, I.J.A., Aguilar, G.F., Camacho, H.I.L., Rocha, G.N.E. and Gonzalez, L.R.F. (2011). Chemical and physicochemical characterization of winter squash (Cucurbita moschata D.). Notulae Botanicae Horti Agrobotanici Cluj-Napoca, 39(1), 34-40. https://doi.org/10.15835/ nbha3915848

Karaoğlu, M.M. and Kotancilar, H.G. (2009). Quality and textural behaviour of par-baked and rebaked cake during prolonged storage. International Journal of Food Science and Technology, 44(1), 93-99. https://doi.org/10.1111/j.1365-2621.2007.01650.x

Khalil, A.H. (1998). The influence of carbohydratebased fat replacers with and without emulsifiers on the quality characteristics of low-fat cake. Plant Foods for Human Nutrition, 52(4), 299-313. https:// 
doi.org/10.1023/A:1008096031498

Kia, S. and Hosseini Ghaboos, S.H. (2018). Development of traditional date cookie formulation using pumpkin puree. Journal of Food Biosciences and Technology, 8(2), 69-78.

Lichtenstein, A.H., Ausman, L.M., Jalbert, S.M. and Schaefer, E.J. (1999). Effects of different forms of dietary hydrogenated fats on serum lipoprotein cholesterol levels. The New England Journal of Medicine, 340(25), 1933-1940. https:// doi.org/10.1056/NEJM199906243402501

McKenzie, J., Schaefer R.L. and Farber E. (1995). The Student Edition of Minitab for Windows. Boston: Massachusetts. Addison-Wesley Publishing.

Meilgaard, M., Civille, G.V. and Carr, B.T. (2007). Sensory Evaluation Techniques. $4^{\text {th }}$ ed. London: Taylor and Francis. https://doi.org/10.1201/b16452

Mohan, P., Mukherjee, I. and Jain, S. (2018). Study on the physico-chemical and sensory characteristics of cookies made using avocado as a fat (Butter) substitute. International Journal of Food Science and Nutrition, 3(1), 68-72.

Provesi, J.G., Dias, C.O. and Amante, E.R. (2011). Changes in carotenoids during processing and storage of pumpkin puree. Food Chemistry, 128(1), 195-202. https://doi.org/10.1016/ j.foodchem.2011.03.027

Rios, R.V., Pessanha, M.D.F., Almeida, P.F., Viana, C.L. and Lannesi, S.C.S. (2014). Application of fats in some food products. Food Science and Technology, 34(1), 3-15. https://doi.org/10.1590/ S0101-20612014000100001

Romero-Lopez, M.R., Osorio-Diaz, P., Bello-Perez, L.A., Tovar, J. and Bernardino-Nicanor, A. (2011). Fiber concentrate from orange (Citrus sinensis L.) bagase: characterization and application as bakery product ingredient. International Journal of Molecular Sciences, 12(4), 2174-2186. https:// doi.org/10.3390/ijms 12042174

Sarıçoban, C., Yılmaz, M.T. and Karakaya M. (2009). Response surface methodology study on the optimisation of effects of fat, wheat bran and salt on chemical, textural and sensory properties of patties. Meat Science, 83(4), 610-619. https:// doi.org/10.1016/j.meatsci.2009.07.010

Schatzel, J. (2018). 10 Substitutes for Butter in Baking. Retrieved on $7^{\text {th }}$ February 2019 from Delishably website: https://delishably.com/dairy/Substitutes-forButter-in-Baking.

Scheuer, P.M., Mattioni, B., Barreto, P.L.M., Montenegro, F.M., Gomes-Ruffi, C.R., Biondi, S., Klipp, M. and Francisco, A.D. (2014). Effects of fat replacement on properties of whole wheat bread. Brazilian Journal of Pharmaceutical Sciences, 50(4),
703-712.

https://doi.org/10.1590/S198482502014000400005

Sharima-Abdullah, N., Hassan, C.Z., Arifin, N. and Huda-Faujan, N. (2018). Physicochemical properties and consumer preference of imitation chicken nuggets produced from chickpea flour and textured vegetable protein. International Food Research Journal, 25(3), 1016-1025.

Sharma, S. and Ramano Rao, T.V. (2013). Nutritional quality characteristics of pumpkin fruit as revealed by its biochemical analysis. International Food Research Journal, 20(5), 2309-2316.

Zhou, C-L., Liu, W., Zhao, J., Yuan, C., Song, Y., Chen, D., Ni Y-Y. and Li, Q-H. (2013). The effect of high hydrostatic pressure on the microbiological quality and physical-chemical characteristics of pumpkin (Cucurbita maxima Duch.) during refrigerated storage. Innovative Food Science and Emerging Technology, 21, 24-34. https://doi.org/10.1016/ j.ifset.2013.11.002 